\title{
Kellie Gonçalves
}

\section{'Cooking lunch, that's Swiss': Constructing hybrid identities based on socio-cultural practices}

\begin{abstract}
This study looks at the discursive construction and negotiation of hybrid identities within binational couples. I analyze conversations produced by Anglophones married to German-speaking Swiss residing in central Switzerland. I employ Bucholtz \& Hall's sociocultural linguistic model (2004, 2005, 2010), which views identity as emergent in social interaction and allows for the investigation of identity at various analytical levels. The analysis shows how individuals interactively position themselves as hybrid based on their co-construction of specific socio-cultural practices of everyday life that concern food (preparation, conservation, cooking). By doing so, individuals draw on various linguistic features, including prosodically marked utterances, pronominal use, and overt mentions of national labels, which index their cultural hybrid identities while at the same time exemplifying the performance of hybridity.
\end{abstract}

Keywords: positioning, identity, binational relationships, interpersonal discourse, hybridity

Kellie Gonçalves: English Department, University of Bern, Länggassstr. 49, CH-3000 Bern 9 , Switzerland, e-mail: goncalves@ens.unibe.ch

\section{Introduction}

Sociolinguistic research conducted on binational couples has largely focused on the topics of language choice, language maintenance, and shift within bilingual or multilingual communities (Gal 1979; Varro 1988; Walters 1996; Refsing 1998; Waldren 1998; Boyd 1998). These studies have not necessarily emphasized the discursive construction of identities per se, but rather have 'bilingual' individuals as their starting point. Studies analyzing dynamic and hybrid identity construction in binational relationships have focused on the 'foreign' spouse only (Heller \& Lévy 1992) as well as couples' joint talk (Piller 2002; Rubin Damari 2010). The aim of this paper, and others in this volume, is to emphasize 
the construction and negotiation of multiple and hybrid identities within the context of bicultural family interaction.

Individuals who are born into one culture, move to another country, and marry someone from a different cultural background are considered to be at a disadvantage in many areas of everyday life, such as social, political, economic (Fitzpatrick 1988), and in many cases linguistic domains. The foreign spouse is not only faced with a different cultural environment, but may be confronted with a new language or languages and local socio-cultural practices that differ from those of their homeland. In essence, this means that individuals are 'living between different cultures' and experience what has been referred to as 'cultural hybridity' (Burke 2009: 4), 'in-between' (Bhabha 1994), or 'third' spaces (Rowe \& Licona 2005).

According to Said, 'all cultures are involved in one another,' and none is considered to be 'single and pure, all are hybrid and heterogeneous' (1999: 112115). Yet individuals living in and experiencing the 'in-between' of cultures often do not see themselves as hybrid (Gonçalves 2010; Bystydzienski 2011). The concept of culture has been subject to debate by many scholars across various disciplines (Keesing 1974; Gudykunst 1994, Scollon \& Scollon 1995; Hofstede 1998; Narayan 2000). Within the context of this study, I use the term culture to be 'the social heritage, including values (beliefs, aspirations, common understandings), norms (rules of conduct), and practices (what people do and say), assumed to be shared by a group with which individuals identify' (Bystydzienski 2011: 3). Ways of behaving are tied to specific socio-cultural practices individuals collaboratively construct and engage in, which over time become part of what Bourdieu refers to as one's habitus (1991). This means that for culturally hybrid individuals such practices may eventually lose their markedness and become part of their daily routines and ways of doing things.

My interest lies in looking at the co-construction of local socio-cultural practices by individuals who are in fact 'living between different cultures' and how these practices contribute to their perceptions of hybridity. The aim of this study is to investigate how American citizens living in Switzerland and married to German-speaking Swiss negotiate and construct hybrid identities outside their home country based on the specific socio-cultural practices they engage in. In the next section, I outline the theoretical framework used, which is followed by a description of my data collection and a brief synopsis of the participants. Afterwards, I look at how three binational couples co-construct hybridity in conversation based on 'cultural food practices,' for example, conservation efforts and preparing lunch. I examine the language resources individuals draw on to position themselves with respect to such practices and how specific features such as pronoun use, direct reported speech, and national identity labels 
index change in the construction of hybrid identities within the context of interpersonal discourse.

\section{Theoretical framework}

The concept of identity is complex, and, as a result, an interdisciplinary theoretical approach is taken. I draw on Bucholtz \& Hall's (2004, 2005, 2010) sociocultural linguistic model of identity, which argues for 'the analytic value of approaching identity as a relational and sociocultural phenomenon that emerges and circulates in local discourse contexts of interaction' (Bucholtz \& Hall 2005: 585-586). In taking such a perspective, their approach 'focuses on both the details of language and the workings of culture and society' (2005: 586). For Bucholtz \& Hall identity is not only constituted in linguistic interaction, but its social salience is also emphasized in that identity becomes the social positioning of self and others (ibid.).

Acknowledging that identity construction takes place on a number of analytical levels, their approach favors the interactional level. They state that

[i]dentity does not emerge at a single analytical level - whether vowel quality, turn shape, code choice, or ideological structure - but operates at multiple levels simultaneously. Our own approach privileges the interactional because it is in interaction that all these resources gain social meaning. (2005: 586)

Within their model, they outline five principles, namely Emergence, Positionality, Indexicality, Relationality, and Partialness. The first two principles emphasize the ontological status of identity in Bucholtz \& Hall's framework that disputes earlier fixed views of identity, while the other three principles offer analytical and discursive approaches to identity construction. The first principle of Emergence rejects the essentialist view of identity, which locates identity primarily within the individual. They claim that

[a]s with performance, culture, and grammar itself, we maintain that identity emerges from the specific conditions of linguistic interaction: identity is best viewed as the emergent product rather than the pre-existing source of linguistic and other semiotic practices and therefore as fundamentally a social and cultural phenomenon. (2005: 588)

Contrary to earlier psychological studies that located identity within the individual or as being based on personality traits (Bhavani \& Phoenix, 1994), identity is regarded here as ephemeral and never static or fixed. In other words, language use becomes the catalyst by which identities are constructed rather than merely reflecting individuals' internal states of being. 
The principle of Positionality rejects the assumption that identity can be explained based on 'broad social categories' such as age, sex, social class, gender, etc. (2005: 591). Instead, they state that identity emerges 'in discourse through temporary roles and orientations assumed by participants, such as evaluator, joke teller, or engaged listener' (ibid.). In fact, these fleeting positions or roles that individuals temporarily occupy (i.e., positionality) 'contribute to the formation of subjectivity and intersubjectivity in discourse' (2005: 591). The principle of Positionality accounts for three analytical levels, where individuals are positioned and identities emerge:

(a) macro-level demographic categories, e.g., gender, age, social class, etc.;

(b) local, ethnographically specific cultural positions, e.g., 'nerd,' 'popular,'

etc. based on lexical choices such as well-established quotative markers

such as go and be like versus the innovative quotative form, be all

(Bucholtz 1999);

(c) temporary and interactionally specific stances and participant roles, e.g., jealousy or disdain based on lexically or prosodically marked utterances.

Although certain acts of positioning may take precedence over others, all three levels may occur simultaneously. By locating and analyzing how individuals position themselves linguistically and others interactionally, we can begin to unravel the complexities of identity construction inter-subjectively accomplished in discourse.

The linguistic forms or resources individuals employ to signal specific identities is known as the principle of Indexicality, which comprises their third principle (2005: 594). The principle of Indexicality is understood to be the 'semiotic link between linguistic forms and social meanings' (2005: 594). Within the realm of identity formation

[i]ndexicality relies heavily on ideological structures, for associations between language and identity are rooted in cultural beliefs and values - that is, ideologies - about the sorts of speakers who (can or should) produce particular sorts of language. (2005: 594)

The principle of Indexicality presupposes that indexical processes can take place at all levels of linguistic structure and use, thus indicating how 'different linguistic means' function to discursively produce identity (ibid.). They claim that identity relations emerge in interaction through several related indexical processes that may include (2005: 594-597):

(a) overt mention of identity categories and labels

(b) pragmatic processes of implicatures and presuppositions regarding one's own or others' identity position, these processes usually require additional inferential work for interpretation 
(c) displayed evaluative and epistemic orientations to ongoing talk, as well as interactional footings and participant roles

(d) the use of linguistic structures and systems that are ideologically associated with specific personas and groups

Their fourth principle, Relationality, which builds on the previous three principles, is considered to be the 'heart' of their model, and it views identity as an inter-subjective accomplishment. Identities are social processes rather than independent or autonomous ones, and such processes circulate within a broad range of identity relations, which they have termed the 'tactics of intersubjectivity'. These tactics consider how issues of culture, power and agency are addressed. They claim that

[i]dentities are intersubjectively constructed through several, often overlapping, complementary relations, including similarity/difference, genuineness/artifice, and authority/ delegitimacy. (2005: 598)

For Bucholtz \& Hall, the tactics of intersubjectivity 'not only call attention to the intersubjective basis of identity, but they also provide a sense of the diverse ways that relationality works through discourse' (2005: 605). Whether considering similarities or differences, realness or fakeness, power or disempowerment, or all these tactics simultaneously, light is shed on how 'identities emerge in relation to other identities within the contingent framework of interaction' (ibid.).

Because identities are inter-subjectively 'produced through contextually situated and ideologically informed configurations of the self and other' (ibid.: 605). They are not only always relational, but partial, which leads to the final principle in their model, that of Partialness. For Bucholtz \& Hall identities may be intentional, deliberate, habitual, negotiated, contested, effects of ideological processes, other's representations, etc., but these constructions are always considered to be partial ones

because identity is inherently relational, it will always be partial, produced through contextually situated and ideologically informed configurations of the self and other. Even seemingly coherent displays of identity, such as those that pose as deliberate and intentional, are reliant on both interactional and ideological constraints for their articulation: Any given construction of identity may be in part deliberate and intentional, in part habitual and hence often less than fully conscious, in part an outcome of interactional negotiation and contestation, in part an outcome of others' perceptions and representations, and in part an effect of larger ideological processes and material structures that may become relevant to interaction. It is therefore constantly shifting both as interaction and across discourse contexts. (2005: 605-606) 
The framework outlined above is one that attempts to develop theoretical approaches to the study of identity by drawing on interdisciplinary fields within the social sciences and humanities. In their model, identity is anchored in interaction at a number of analytical levels, none of which can be accounted for within a single analysis. Adopting an emergent approach to identity construction within this study allows me to highlight how various linguistic resources index different local positions on the micro-level of conversation, which are inevitably shaped by the larger macro level ideologies and dominant discourses (Fairclough 1995) that individuals draw on. ${ }^{1}$

\section{Data, participants, and site of study}

What makes Bucholtz \& Hall's model particularly useful for the present analysis is that it highlights the role of emergent identities within interaction by drawing on a variety of language resources and sociolinguistic markers, some of which include labeling, stance taking, style marking, and code-choice. These linguistic markers serve to signal temporary positions individuals take up or refute as well as indexing local dimensions of identities, and within this study, hybrid identities in particular. The data result from conversations carried out with participants as well as from field notes and participant observation, which assisted in providing background information on participants that has been incorporated into this analysis. The main method employed for data generation is referred to as 'conversations with a purpose,' which have been defined as a form of 'unstructured interviewing' that may 'appear to be without a structure, but nevertheless the researcher has to establish a framework within which the interview can be conducted; the unstructured interview is flexible but also controlled' (Burgess 1982: 107). This means that while there was not a specific list of questions prepared, I was well aware of the themes I wanted to address, e.g., existing socio-cultural differences between the individuals' homeland and Switzerland.

The conversations were carried out with nine couples. I gained access to all of my participants through the 'friend of a friend' method (Boissevain 1974;

1 For Fairclough, discourses are ways of 'signifying a particular domain of social practice from a particular perspective' (1995: 14), which are always ideologically driven and influence how individuals position themselves and others in interaction. The positioning of individuals takes place within conflicting discourses (Baxter 2002), so much so that they may experience what Billig et al. (1988) refer to as 'ideological dilemmas' or tensions between opposing viewpoints (Kendall 2007: 126). 
Milroy 1980), subsequent to talking with my neighbors, an American woman married to a Swiss man. Conversations were conducted in English and lasted between one and one-and-a-half hours, and a total of 15.5 hours of recorded conversation was collected. The recorded material was transcribed in broad notation and resulted in a corpus of 125,395 words.

The transcripts were coded manually and divided into four main topics emerging in all the conversations, i.e., everyday socio-cultural practices, couple discourse (speaking to each other), identity claims (implicit identity claims, explicit identity claims), and language choice and language practices. For the purpose of this paper, I focus on the everyday socio-cultural practice of meal preparation and cooking, which is often tied to the implicit and explicit identity claims made by husbands and wives, and on the participants' co-construction and performance of hybrid identities.

I specifically look here at the transcriptions of three American-Swiss couples (Timo and Clara, Dale and Thorsten, and Cathy and Simon). I focus on these three couples only for two reasons. The first is that all of the female participants were homemakers or stay-at-home mothers during the time of the recorded sessions. As a result, their talk and the positions they adopt or refute can be examined against the backdrop of traditional discourses of asymmetrical gender relations in which women are dominant in the home and men are career oriented and breadwinners (Potuchek 1997; Kendall 2007). Secondly, because of the asymmetrical relations of the spouses, the socio-cultural practices of meal preparation and cooking emerged as a common theme or a starting point where cultural similarities and differences emerged and identities were negotiated. All three couples reside in the Interlaken area, located in central Switzerland, 55 kilometers south-east of the Swiss capital Bern.

Timo (44) and Clara (45) had been living in Switzerland for nine years at the time of our conversation, but had lived in Basel for two years during the late 90 s before moving to the States for two years, where their two children were born. Timo is originally from Lucerne, and Clara hails from San Pedro, California. She has an MA in social work. During their time in the States, Timo completed his MA in social work and, at the time of our conversation, had just completed his PhD at the University of Basel. He is a school administrator in Bern in the field of social work. Since moving back to Switzerland, Clara had been working part-time as an English teacher, but had recently decided to become a full-time mother. Timo and Clara speak English as a couple. Clara speaks English with their children while Timo speaks Swiss German with them.

Dale (46) and Thorsten (45) had been married for three years during the time of our conversation. Dale is from Orange County, California. She obtained a BS in Business Administration and Marketing and worked in Hawaii as a sales 
representative for developed housing for nine years. Afterwards, she returned to San Diego and worked for a pharmaceutical company before she earned her real estate license. She continued working in the real estate business until she traveled to Interlaken in 2002, where she met her future husband Thorsten and became a homemaker. Thorsten (45) was born in Aarberg in the canton of Bern. He attended a technical school where he studied architecture and at the time of our conversation had been a resident of Interlaken for 20 years. He is coowner of a large international real estate agency franchise and also works as an architect. The couple speak English together and they do not have children.

Cathy (43) and Simon (40) live in Bönigen and had been married for twelve years at the time of our conversation. They have two children Sarah and Billy, aged 11 and 9 at the time of the recordings. Cathy is originally from San Diego, California, but she has been living in Switzerland for the last twenty years. Born into an intercultural family - her father is Swiss and her mother American she grew up on a farm on the outskirts of San Diego. Despite having a Swiss father, she did not speak Swiss German while growing up, but learnt most of it subsequent to her move to Interlaken in 1989. Cathy found employment in a souvenir shop early on, although her working week decreased drastically after her children were born. At the time of our interview, she was working there sporadically to help the owners. Simon was born and raised in Bönigen. After finishing primary school, he did an apprenticeship as a foreman. While he currently works as a foreman, he is also an official farmer according to federal Swiss regulations. Together, this couple speaks English, although their family language might be labeled as 'mixed.' While Cathy speaks English with her children, Simon converses with them in Bernese German only.

\section{Co-constructing hybridity}

In this section, I analyze three excerpts from the conversations with these three American-Swiss couples that revolve around certain socio-cultural practices such as food conservation, meal preparation, and partaking in family lunches. The relevant socio-cultural practices are discursively constructed as Swiss, and they emerge and are shaped by traditional discourses of asymmetrical gender relations in couples' joint talk about them. By engaging in this discourse, husbands and wives position themselves and each other as certain types of individuals within the context of the unfolding conversation, where altered and hybrid identities emerge. 


\subsection{Not wasting food}

In excerpt 1 Clara admits to engaging in what she calls Swiss habits and positions herself as changed compared to her American friends. This excerpt begins shortly after Clara and her husband Timo have been discussing the benefits of having lived in both the USA and Switzerland:

1. CLA: and that's good and also, in fact we said that when we first met that it would be important

2. for timo to live in my country too, so we understand each other's backgrounds, we

3. always kind of said that and it did work out that way, i don't think there's been a time

4. where i've said, no, i can't do this anymore

5. KEL: $\mathrm{mhm}$, and in terms of i mean, now that you speak swiss german, do you feel that you

6. have some sort of swiss identity?

7. CLA: (4.0) hmmm, i don't know? (2.0) probably not

8. KEL: $\mathrm{mhm}$

9. CLA: $i$ have swiss- $i$ have swiss erm, $i-i-i$ have swiss habits that $i$ think are good

10. KEL: like what?

11. CLA: like recycling is good and cooking certain swiss foods, erm, i like that we have lunch

12. KEL: $\mathrm{mhm}$

13. TIM: not wasting bread @@@

14. CLA: not wasting anything!

15. TIM: she drives me crazy now

16. KEL: why?

17. TIM: she took that from my mother@@@@

18. CLA: i'm fanatical about not wasting food and i will- $i$ will not leave- if- if anybody leaves

19. food on the plate and all these little things you know? like

20. TIM: yes, she's swiss isn't she?

21. CLA: and if we have visitors from america, i realize they always leave food on their plate and $\mathrm{i}$

22. always did that too and- and- but- now it's one of those little swiss things you know?

23. TIM: well, i don’t leave it either, [now- now she’s going over@@@@

24. CLA: [no you don't

25. KEL: oh, so now she’s too swiss for ya? @@@

26. TIM: with the bread 'cause with bread i can't eat it anymore after a certain period

27. CLA: and i've tried making things out of that old bread you know, so i'm very conservational 
28. that way and also i don't like driving, i never liked driving that much, i love taking trains

29. KEL: $\mathrm{mhm}$

30. CLA: there are certain swiss things

31. TIM: mhm [like riding the bike is- walking is becoming more natural for you

32. CLA: [but my personality $i$ think is still american

For the participants in this study, speaking the local Bernese dialect made them feel more integrated in their local community and to some extent more Swiss than individuals who did not speak any Bernese. This correlation between language use and the ideological expectations of specific language users coincides with what Bucholtz \& Hall refer to as 'authentication' within their definition of intersubjectivity. Knowing that Clara spoke the local dialect quite well prompted my question about a Swiss identity, which she contemplates in her four second pause (line 7), followed by the epistemic uncertainty marker $i$ don't know (line 7). Clara admits to engaging in certain socio-cultural practices that she perceives and evaluates both as positive and as Swiss such as recycling, cooking, and having lunch (line 11). By claiming that these habits are those she considers Swiss, Clara suggests that these practices are not usual in her home country. Subsequent to Clara's admittance, Timo adds to Clara's list of habits by stating not wasting any bread (line 13) and therefore positioning his wife as conscientious and perhaps even thrifty and eco-friendly. Clara accepts this positioning and confirms her pro-active efforts when she describes herself as both fanatical and very conservational when it comes to food (lines 18 and 27).

For both Timo and Clara, being economical and eco-friendly are ideologically associated and co-constructed as Swiss. This becomes apparent when Timo refers to his Swiss mother (line 17) and the conservational habits she passed on to her daughter-in-law. By overtly drawing on the national label 'Swiss,' Timo positions his wife as such (line 20). Clara does not rebut or take up Timo's positioning of her, but continues to clarify her stance regarding food waste and the construction of Swissness by comparing and evaluating their American visitors' and her and Timo's way of doing things. Clara draws on overt mentions of national identity labels to make this differentiation, but her use of the first person plural inclusive pronoun we and the exclusive thirdperson pronoun they (line 21) expresses distancing (De Fina 2003) and positions Clara and Timo as different from their American friends. Clara's pronoun use serves as a marker of dissimilarity and indexes individuals' distinct identities based on the very different socio-cultural daily practices that she and Timo engage in compared to their American friends. Within the context of interaction, pronouns are considered to be micro-level features of talk (Cramer 2010), which function to index particular identities, in this case, socio-cultural features of 
what constitutes both being 'American' and being 'Swiss.' For Clara, her American friends are constructed as less conscientious about food conservation (line 21). And while she confesses to doing the same in the past, her behavior has altered (line 22). Clara accepts that there are certain practices she considers to be Swiss (line 30), but asserts that her personality is still American. Her use of the epistemic uncertainty marker $i$ think once again indexes her insecurity about her hybrid identity, which in this extract is co-constructed by herself and Timo.

\subsection{My California lifestyle}

In excerpt (2), Thorsten and Dale are discussing some of the Swiss habits Dale has adopted since her move to Switzerland and her marriage to Thorsten two years prior to our conversation. In this extract, I introduce the topic of making lunches (line 7) since this was one practice Dale was learning and coming to terms with, but not particularly happy about. Her dissatisfaction with her current situation had to do with the fact that prior to residing in Switzerland, Dale had been a successful professional in the U.S., who had traveled extensively and was now struggling with her changed identity from a former professional, financially independent woman to a financially dependent homemaker and wife:

1. THO: i think it's difficult to say if you have like- if you took like swiss habits or so, if you

2. would ask her friend from california in tens years, if she thinks that dale

3. took some swiss habits then she would probably say, yeah, there is this and that and

4. that

5. DAL: $\mathrm{mhm}$

6. THO: without realizing for you

7. KEL: yeah, some swiss habits that you've taken on or practices, i mean you now make lunches,

8. i'm sure you didn't do that when you were living in california?

9. DAL: yeah, then when i go back to california, i don’t do it either @@@, i go back to living my

10. california lifestyle there, but erm, yeah, i think you know- $i$ think theythey would be

11. surprised that now i know how to make a kä::s- kä::skuche and i know how to make erm,

12. you know erm, apfelkuche and erm, all the other- and the berner platte, i mean i learned 
13. you know? i'm learning how to make swiss style food and fondue and

14. THO: rö::sti

15. DAL: rö::sti, ja and all that stuff, so yeah, they- i think they'll be shocked if you- now if $i$

16. ever try to prepare a meal for them over there, they'd go, wo::w! you never knew how to

17. make anything before? so now, yeah, i know how to make a few swiss things

In this excerpt, Thorsten's first utterance makes it clear that he may not be the best judge of his wife's Swiss habits and adopted socio-cultural practices. This becomes evident through his use of the epistemic uncertainty marker, $i$ think it's difficult to say (line 1). By referring to Dale's Californian friend, he positions himself as unable to make such an assessment perhaps due to his subjective distance or to the fact that Dale's Californian friend (1. 2) has known Dale longer than her own husband and has not witnessed the gradual changes Dale has undergone. Thorsten's view of his wife's changed behavior is conveyed through the hedge marker probably and the prosodically marked direct reported speech clause she would probably say, yeah, there is this and that and that (lines 3-4). Thorsten's utterance can be interpreted to suggest that in ten years time, his wife will have indeed taken on Swiss habits, many of which may not become obvious to Dale (line 6).

Dale's minimal response indexes her alignment to her husband's depiction of the situation, but when confronted about making lunches in California, she states $i$ go back to living my California lifestyle there (lines 9-10) suggesting that she returns to her previous ways of life that do not include preparing meals. This is accomplished by her use of the possessive determiner my, and the deictic adverb there, both of which index her distinct way of life in California compared with her life in Switzerland. Dale admits to being able to go back to her Californian lifestyle and, as a result, is consciously aware of the various socio-cultural practices she engages in and her ability to switch and adapt to her cultural surroundings, thus constructing her identity as culturally hybrid but also geographically and regionally salient. Dale's utterance further positions her as a flexible individual who can change her behavior depending on the country she is in. Dale's past California lifestyle was correlated with her successful profession as a real estate broker, which entailed long workdays filled with business meetings and social events in the evenings.

At one point in our conversation she admits to learning how to cook subsequent to her arrival in Switzerland. In fact, many of the traditional Swiss dishes are listed by code-mixing and employing the local Bernese dialect in kä::skuche, apfelkuche, berner platte and rö::sti (lines 12, 13 and 15). Dale's prosodically 
marked utterances of kä::skuche and rö::sti indicated by vowel lengthening is a brief performance (Butler 1990; Bucholtz 1995; Jaffe 2000) of Dale’s ability to 'do Swiss,' but more specifically Bernese (Haas 1992, 2000; Rash 1998, 2003), and therefore positioning her as such. ${ }^{2}$ For Dale, going back to living her California lifestyle means abandoning the everyday duties of a homemaker and enjoying the pleasures of the more convenient American way of life, a topic we discussed later in our conversation. Dale's changed and hybrid identity is further constructed by means of direct reported speech, which is prosodically marked and functions to depict the climax of her story (Clift 2000; Golato 2000). It also functions to dramatize (Mayes 1990; Myers 1999) her friends' surprised reaction (lines 16-17) of her changed identity from an independent and successful professional, who did not know how to cook, to a homemaker, engaging in the socio-cultural practice of making daily lunches for her husband as well as knowing how to prepare several traditional Swiss meals successfully. Dale and Thorsten's talk signals the temporary stances and different ways in which they position themselves, each other, and their friends by drawing on certain lexical choices as well as prosodically marked utterances in their co-construction of hybridity.

\subsection{We cook together with grandma}

In excerpt (3), Cathy and Simon discuss how lunch is prepared on a daily basis together with Simon's mother and thereby jointly construct their meals and their families as traditionally Swiss. Shortly before this excerpt, Cathy was discussing her childrearing duties, which prompted my question about making lunches:

1. KEL: so do you make the lunches during the week and stuff?

2. CAT: $\mathrm{mhm}$, erm we cook together with grandma

3. SIM: yeah

4. KEL: oh

5. CAT: yeah, so we talk about it every morning, what should we cook? and oh gosh, this

2 I use the term 'doing' Swiss,' which can be understood as synonymous to 'performing in a Swiss way.' In this context, Dale's language choice and use of the Bernese dialect highlights the relationships between herself and the audience (her husband and interviewer) as well as indexing her identity as hybrid (Jaffe 2000). 
6. cooking thing again and then erm, yeah- usually

7. SIM: she makes the soup

8. CAT: she does the soup and this and that and i do the meat and but it's a full on lunch

9. and this is a really, $i$ think it's good that- that we eat a real (meal)

10. SIM: we eat still the regular, traditional swiss way, we

11. CAT: yeah we eat much better because we cook [together

12. SIM:

[because my father is old

13. CAT: then there's a reason to if $i$ was- if it was just me and the kids and simon was off

14. working, i'm sure it would be a much quicker, easier lunch and not as healthy, this way

15. we eat a really warm lunch every day from soup to potatoes to meat to vegetables

16. SIM: but this is also a- in switzerland, you know where these habits arechange into erm,

17. [just quick lunch and quick

18. CAT: [yeah, this is something that i learned, that $i$ [couldn't

19. SIM:

[more and more jobs are further away

20. and all that is changing too slowly- already is, so it's you know?

21. CAT: mhm, it's a good tradition, this is something that i've also learned

This excerpt highlights the everyday socio-cultural practice of food preparation and eating family meals at lunchtime that are constructed as traditionally Swiss (line 10), but it also discursively depicts Cathy's metamorphosis of a changed individual who has not only learned how to do certain socio-cultural practices, but also consciously continues to maintain them (lines 18 and 21).

Cathy's initial response to my question instigates a joint narrative in which both Cathy and Simon reconstruct a typical scenario of how two women (Cathy and her mother-in-law) cooperate in preparing lunch. Cathy's response we cook together with grandma (line 2) is an explicit reference to her mother-in-law, who lives next door. In fact, their joint effort is a daily routine. This becomes obvious through her use of the inclusive we pronoun, which indexes social closeness, as well as through the use of the interjection oh gosh (Myers 1999a), and the direct reported speech clauses what should we cook?, and this cooking thing again (lines 5-6). Her use of these linguistic constructions are prosodically marked so as to convey authenticity of her and her mother-in-law's actual speech event (Coulmas 1986) as well to represent the development of their conversation and Cathy's stance (Tannen 1989; Holt 1996; Niemelä 2005). The social meaning indexed by these constructions positions Cathy as a cooperative team player in the game of lunch, consulting her mother-in-law about food preparation. 
Following this, Cathy and Simon reconstruct the division of labor allocated between Cathy and her mother-in-law (lines 7 and 8). Cathy's use of the modifier full on in it's a full on lunch (line 8) implies that their meals are hearty, satisfying, and quite an ordeal. It is also a socio-cultural practice that she finds good since, as a family, they eat real meals and end up eating much better (line 11). Her positive evaluation positions her and her family as health-conscious individuals, which is a different positioning from Americans and their unhealthy eating habits (an earlier topic in the conversation prior to the excerpt given here). Simon's comment we eat still the regular, traditional Swiss way (line 10) positions him, Cathy, and their family as unique by his overt mention of the national label 'Swiss.' It suggests that certain cultural family values are adhered to although in reality they may be dissimilar to other Swiss families since they have managed to maintain customary midday meals. For Simon, participating in family lunches gains meaning since these traditions are slowly changing due to the fast-paced lifestyles of current Swiss society (line 17). Simon's reference to the macro-level demographic category of age in old father positions him as a dedicated and caring son. Cathy positions herself as grateful and open to their traditional lunches, a local everyday socio-cultural practice she admits to having learned, taken up, and ultimately values. This is apparent when she employs anaphoric reference by using the deictic determiner this in this way (line 14) tacitly implying 'the Swiss way,' or perhaps even 'their way.' Their way is co-constructed as traditionally Swiss and therefore also indexes Cathy's identity as changed and hybrid based on the learned and adopted sociocultural practices she engages in daily since her marriage to Simon.

\section{Discussion}

In the analysis, I have presented diverse ways in which three binational couples co-construct and perform their cultural hybrid identities. In employing Bucholtz \& Hall's socio-cultural linguistic model, it was possible to see just how much variation exists between these couples in terms of the language resources and the range of linguistic features employed in positioning themselves and others within the conversations recorded for the purposes of my research project. These ranged from explicit national identity labels to the use of micro-level features such as pronouns indexing not only how wives and husbands position themselves as certain types of individuals, but also how they position others, e.g., as friends or as visitors from their home countries, in order to construct identity differences. 
The cultural differences and ensuing socio-cultural practices were constructed through individuals' use of overt national and cultural labels such as American and Swiss. They were also constructed through prosodically marked utterances and direct reported speech to position their temporary stances within the conversation as well as their participant roles and those of their interlocutors, whether friends or family members. Individuals draw on direct reported speech, which functions to convey authenticity (Coulmas 1986; Li 1986; Mayes 1990; Holt 1996, 2000, 2009), and to represent individuals' involvement (Tannen 1989). The use of direct reported speech also exemplifies the development of conversation among interlocutors (Holt 1996; Niemelä 2005), e.g., Cathy and her mother-in-law, and the climax of Dale's story (Drew \& Holt 1988; Clift 2000; Golato 2000). It also helps to dramatize individuals' reactions to cultural hybridity (Mayes 1990; Myers 1999b), for example, Dale's friends' reactions concerning her ability to cook as a result of living in Switzerland.

The use of prosodically marked utterances is one way for individuals to position themselves and each other in talk and to signal their respective stances (Günthner 1999). Another way individuals position themselves and each other is through their implicit mention of macro-level demographic categories such as gender and age. This emerges within the context of Clara and Timo's conversation, in which he employs an overt national label of 'Swiss' to position his wife based on her food conservation efforts and refers to his Swiss mother as the reason for such eco-friendly efforts.

In the conversation with Simon and Cathy, Simon also attributes the reason for engaging in traditional Swiss family meals to his father, thus positioning him and Cathy as caring and adhering to cultural and family values. Prosodically marked utterances and macro-level demographic categories are listed under the Positionality principle within Bucholtz \& Hall's model and are two distinct ways in which diverse and cultural hybrid identities emerge and are coconstructed among the individuals in this study.

Within their Indexicality principle, the indexical process of labeling and overt mentions of 'Swiss' and 'American' also emerge. This is to be expected since individuals were confronted during the research with the construction of a Swiss and a hybrid identity, leading them to draw on national labels. In my conversation with Dale and Thorsten, however, a more regional and geographically situated identity is constructed when Dale makes a claim to her very own Californian lifestyle. Dale's ability to switch from her Californian lifestyle to her cultural hybrid one is one she exemplifies linguistically by code-mixing, i.e., by drawing on the local Bernese dialect. Her use of Bernese within this context indexes her local cultural hybrid identity as changed. This example falls under the Indexicality principle, but also merges into the Relational principle where 
identities are inter-subjectively constructed through overlapping and complementary relations, such as adequation and distinction, and authentication and denaturalization. Code-mixing illustrates how processes of social and cultural differentiation are played out and performed in interaction (Jaffe 2000). This is indeed the case with Dale, whose cultural hybrid identity emerges through the language resources available to her. She has acquired this over time as a result of living in a binational relationship.

The Partialness principle recognizes that any account of identity will always be partial since identities are context-dependent and individuals reveal certain facets of their identities to others in different situations. This is indeed the case in this restricted data set in which the co-construction of cultural hybridity between husbands and wives in a binational relationship is accomplished within the context of discussing certain socio-cultural practices related to food preparation, conservation efforts, and family lunches. All of these practices are co-constructed as Swiss and seen against the backdrop of dominant traditional discourses. Because all three women in this study were homemakers or stay-athome mothers, one of their many domestic duties entails making meals and more importantly, having lunch, and this is then constructed by them as the yardstick against which the notion of 'traditional Swiss' is measured. In this way, the saliency of this particular everyday socio-cultural practice is considered to be distinctly different from the socio-cultural practices of the American wives' home country.

\section{Conclusion}

In this study I have looked at how culturally hybrid identities are co-constructed in three binational couples based on the everyday socio-cultural practices revolving around food such as meal preparation, conservational efforts, and cooking. In accounting for how 'living between cultures' is done among different binational couples, it has become clear that certain socio-cultural practices such as cooking lunch and engaging in traditional family meals are ideologically associated with a particular cultural group, in this case the Swiss. Engaging in different practices and coming to terms with an altered and hybrid identity may be accepted and embraced, as is the case with Clara, Dale, and Cathy.

In accounting for the variation of language resources and linguistic features present within this study that are used to co-construct individuals' cultural hybrid identities, I have employed Bucholtz \& Hall's socio-cultural linguistic model, which views identity as emergent and as a product of social interaction. Because their model accounts for identity construction at various analytical 
levels, this allowed me to illustrate how identity works and, in particular, how cultural hybridity is co-constructed, negotiated, and performed among binational couples, where the positioning of self and other continuously shifts on the micro-level of conversation. Analyzing the indexical process of labeling, code-mixing, pronominal use, or prosodically marked utterances that individuals' employ to position themselves and others in discourse exemplifies the various analytical layers at which identities can emerge. And while it is impossible to account for identity 'as a whole,' I have shown how individuals living in a binational relationship come to terms with their hybrid cultural identities by discursively co-constructing this notion and, simultaneously, performing hybridity by drawing on an array of language resources and linguistic features.

\section{Bionote}

Kellie Gonçalves holds a Ph.D. in English Linguistics from the University of Bern, Switzerland. She teaches in both the BA and MA programs in Modern English Language in the Department of English Languages and Literatures at the University of Bern. Her research interests include identity studies and diasporic communities, semiotic landscapes, ELF, historical linguistics, discourse and tourism studies, and stylistics. Her monograph, entitled Conversations of intercultural couples (Akademie Verlag), will be out in June 2013.

\section{References}

Baxter, Judith. 2002. Competing discourses in the classroom: A post-structuralist discourse analysis of girls' and boys' speech in public contexts. Discourse and Society 13(6). 827-842.

Bhabha, Homi. 1994. The location of culture. London: Routledge.

Bhavani, Kum-Kum \& Ann Phoenix. 1994. Shifting identities and shifting racisms: Introduction. In Kum-Kum Bhavani \& Ann Phoenix (eds.), Shifting identities and shifting racisms, 5-18. London \& Thousand Oaks: Sage Publications Ltd.

Billig, Michael, Susan Condor, Derek Edwards, Mike Gane, David Middleton \& Alan Riley. 1988. Ideological dilemmas: A social psychology of everyday thinking. Thousand Oaks: Sage Publications Ltd.

Boissevain, Jeremy. 1974. Friends of friends: Networks, manipulators and coalitions. Oxford: Basil Blackwell, 1974.

Bourdieu, Pierre. 1991. Language and symbolic power. (Ed. J. B. Thompson, Trans. G. Raymond \& M. Adamson). Cambridge: Polity Press.

Boyd, Susan. 1998. North Americans in the Nordic region: Elite bilinguals. International Journal of the Society of Language 133. 31-50. 
Bucholtz, Mary. 1999. 'Why be normal?' Language and identity practices in a group of nerd girls. Language in Society 28(2). 203-223.

Bucholtz, Mary \& Kira Hall. 2004. Language and identity. In Alessandro Duranti (ed.). A companion to linguistic anthropology, 369-394. Oxford: Blackwell.

Bucholtz, Mary \& Kira Hall. 2005. Identity and interaction: a sociocultural linguistic approach. Discourse Studies 7(4-5). 585-614.

Bucholtz, Mary \& Kira Hall. 2010. Locating identity in language. In Carmen Llamas \& Dominic Watt (eds.), Language and identities, 18-28. Edinburgh: Edinburgh University Press.

Burgess, Robert G. 1982. The unstructured interview as a conversation. In Robert Burgess (ed.), Field research: A sourcebook and field manual, 107-110. London: Routledge.

Burke, Peter. 2009. Cultural hybridity. Cambridge: Polity Press.

Butler, Judith 1990. Gender trouble. New York: Routledge.

Bystydzienski, Jill, M. 2011. Intercultural couples: Crossing boundaries, negotiating identities. New York: New York University Press.

Clift, Rebecca. 2000. Stance-taking in reported speech. Essex Research Papers in Linguistics, 32. 1-31.

Coulmas, Florian. 1986. Reported speech: Some general issues. In F. Coulmas (ed.), Direct and indirect speech, 1-28. Berlin: Mouton de Gruyter.

Cramer, Jennifer. 2010. 'Do we really want to be like them?': Indexing Europeanness through pronominal use. Discourse and Society 21(6). 619-637.

De Fina, Anna. 2003. Identity in narrative: A study of immigrant discourse. Amsterdam and Philadelphia: John Benjamins Publishing Company.

Drew, Paul \& Elizabeth Holt. 1988. Complainable matters: The use of idiomatic expressions in marking complaints. Social Problems 35. 398-417.

Fairclough, Norman. 1995. Critical discourse analysis. London \& New York: Longman.

Fitzpatrick, Mary Anne. 1988. Between husbands and wives: Communication in marriage. Newbury Park, CA: Sage.

Gal, Susan. 1979. Language shift: Social determinants of linguistic change in bilingual Austria. New York: Academic Press.

Golato, Andrea. 2000. An innovative German quotative for reporting embodied actions: Und ich so / und er so 'and I'm like / and he's like'. Journal of Pragmatics 32. 29-54.

Gonçalves, Kellie. 2010. Negotiating identities and doing Swiss in intercultural couples. In Karen Junod and Didier Maillat (eds.), Performing the Self, 75-89. Tübingen: Narr.

Gudykunst, William, B. 1994. Bridging differences: Effective intergroup communication. London, Thousand Oaks \& New Delhi: Sage Publications, Inc.

Günthner, Susanne. 1999. Polyphony and the 'layering of voices' in reported dialogues: An analysis of the use of prosodic devices in everyday reported speech. Journal of Pragmatics 31. 685-708.

Haas, Walter. 1992. Mundart und Standardsprache in der deutschen Schweiz. In J. A. v. Leuvensteijn \& J. B. Berns (eds.), Dialect and standard language - Dialekt und Standardsprache in the English, Dutch, German and Norwegian Language Areas: Proceedings of the colloquium 'Dialect and Standard Language', Amsterdam, 15-18 October 1990, 312-336). Amsterdam: Royal Netherlands Academy of Arts and Sciences.

Haas, Walter. 2000. Die deutschsprachige Schweiz. In H. Bickel \& R. Schläpfer. Die viersprachige Schweiz. $2^{\text {nd }}$ (edn.), 57-139. Aarau: Sauerländer.

Heller, Monica \& Laurette Lévy. 1992. Mixed marriages: Life on the linguistic frontier. Multilingua 11(1). 11-43. 
Hofstede, Geert, H. 1998. Masculinity and femininity. London, Thousand Oaks \& New Delhi: Sage Publications.

Holt, Elizabeth. 1996. Reporting on talk: The use of direct reported speech in conversation. Research on Language and Social Interaction 29(3). 219-245.

Holt, Elizabeth. 2000. Reporting and reacting: Concurrent responses to reported speech. Research on Language and Social Interaction 33(4). 425-454.

Holt, Elizabeth. 2009. Reported speech. In S. D’hondt, J.-0. Östman \& J. Verschueren (eds.), Pragmatics of interaction: Handbook of pragmatics highlights, vol. 4. 190-205. Benjamins.

Laver, John. 1975. Communicative functions in phatic communion. In A. Kendon, R. M. Harris \& M. R. Key (eds.). Communication in face-to-face interaction, 73-92. Berlin: Mouton.

Li, Charles, N. 1986. Direct and indirect speech: A functional study. In F. Coulmas, F. (ed.), Direct and indirect speech, 29-45. Berlin: Mouton de Gruyter.

Jaffe, Alexandra. 2000. Comic performance and the articulation of hybrid identity. Pragmatics 10(1). 39-59.

Keesing, Roger, M. 1974. Theories of culture. Annual Review of Anthropology 3. 73-97.

Kendall, Shari. 2007. Father as breadwinner, mother as worker: Gendered positions in feminist and traditional discourses of work and family. In Deborah Tannen, Shari Kendall \& Cynthia Gordon (eds.), Family talk: Discourse and identity in four American families, 123-163. Oxford: OUP.

Mayes, Patricia, D. 1990. Quotation in spoken English. Studies in Language 14. 325-363.

Milroy, Lesley. 1987 [1980]. Language and social networks. $2^{\text {nd }}$ ed. Oxford: Blackwell Publishing.

Myers, Greg. 1999a. Functions of reported speech in group discussions. Applied Linguistics 20(3). 376-401.

Myers, Greg. 1999b. Unspoken speech: Hypothetical reported discourse and the rhetoric of everyday talk. Text 19(4). 571-590.

Narayan, Uma. 2000. Undoing the 'package picture' of cultures. Signs: Journal of Women and Culture and Society 25(4). 1083-1086.

Niemelä, Maarit. 2005. Voiced direct reported speech in conversational storytelling: Sequential patterns of stance taking. SKY Journal of Linguistics 18. 197-221.

Piller, Ingrid. 2002. Bilingual couples talk: The discursive construction of hybridity. Amsterdam: John Benjamins.

Potuchek, Jean, L. 1997. Who supports the family?: Gender and breadwinning in dual-earner marriages. Stanford: Stanford University Press.

Rash, Felicity. 1998. The German language in Switzerland: Multilingualism, diglossia and variation. Bern: Peter Lang AG.

Rash, Felicity. 2003. The German language in Switzerland. In J. Charnley, J. \& M. Pender (eds.), Living with languages: The contemporary Swiss model, 107-127. Bern: Peter Lang.

Refsing, Kirsten. 1998. Gender identity and gender role patterns in cross-cultural marriages: The Japanese-Danish case. In Rosemary Anne Breger \& Rosanna Hill (eds.), Crosscultural marriage: Identity and choice, 193-208. Oxford: Berg.

Rowe, Aimee Carillo \& Adela C. Licona. 2005. Moving locations: The politics of identities in motion. NWSA Journal 17(2). 11-15.

Rubin Damari, Rebecca. 2010. Intertextual stancetaking and the local negotiation of cultural identities by a binational couple. Journal of Sociolinguistics 14(5). 609-629. 
Said, Edward, W. 1999. Out of place: A memoir. New York: Vintage Books.

Scollon, Ron \& Scollon, Suzie, Wong. 1995. Intercultural communication: A discourse approach. Cambridge Mass. and Oxford: Blackwell Publishers Inc.

Tannen, Deborah. 1989. Talking voices: Repetition, dialogue, and imagery in conversational discourse. Cambridge: Cambridge University Press.

Varro, Gabrielle. 1988. The transplanted woman: A study of French-American marriages in France. New York: Praeger.

Waldren, Jackie. 1998. Crossing over: Mixing, matching and marriage in Mallorca. In R. Berger \& R. Hill (eds.), Cross-cultural marriage: Identity and choice, 33-48. 0xford: Berg.

Walters, Keith. 1996. Gender, identity, and the political economy of language: Anglophone wives in Tunisia. Language in Society 25(4). 515-555. 